\title{
MONITORING NATIONAL INNOVATION PERFORMANCE: GOING BEYOND STANDARDIZED RANKINGS
}

\author{
JOHANNES GADNER AND JÜRGEN JANGER \\ D0I: 10.22163/fteval.2020.463
}

\section{INTRODUCTION ${ }^{1}$}

I nnovation performance has become increasingly important for governments as they search for ways to stimulate the economy and to address pressing societal challenges (e.g. Edler/Fagerberg 2017; Androsch/Gadner 2015; Aghion/David/Foray 2009). Thus, in recent years a variety of innovation performance rankings have been developed to measure performance levels and benchmark them against other countries. Those are, hence, closely watched by policymakers and are frequently perceived as a neutral gauge of a country's innovation performance (Schibany/Streicher 2008). However, standard rankings such as the European Innovation Scoreboard (EIS) or the Global Innovation Index (GII) in general apply a standardised set of indicators to all countries ranked without taking account of country specific weaknesses or strengths. For example, the Austrian government has been using the benchmark defined by the EIS to compare the Austrian innovation performance in the leading countries in Europe. Yet, the EIS should not be used as the only criterion to assess the effects of innovation efforts due to well-known shortcomings which result both from its construction as a composite indicator and from problems related to the substance of the indicators which make up the EIS summary index.

Concerning the latter, it underestimates e.g. the effects of innovation activities because it does not include indicators for improvement in the existing sectors, i.e. intra-sectoral structural change or sectoral upgrading; see also the more detailed explanations further below in this paper (Janger et al. 2017). Several of the other indicators used may lead to misleading interpretations. By way of example, the indicator measuring the share of knowledge-intensive services exports in total services exports penalizes countries with a large tourism sector such as France or Austria; some of the indicators drawn from the Community Innovation Survey are quite volatile or yield surprising results, e.g. that the share of new to market innovations (a proxy for novelty) is higher in some Eastern European countries than in Germany.

On top of these problems of substance, the construction of the EIS also entails drawbacks. First, it aggregates input and output indicators, so that ample inputs can compensate for weak outputs. (e.g. Edquist et al. 2018). Second, composite indicators are prone to the discussion on appropriate weighting of the indicators - should all indicators carry the same weight in determining innovation performance or are some more important than others? Grupp and Schubert (2010) have pointed out that different weighting schemes can give rise to very different country rankings. They recommend complementing composite indicators by multidimensional representations of the issues leading to the performance in the aggregate indicator, i.e. explaining to policy makers why the performance arises. This would safeguard the communication function of composite indicators which due to their simplicity la simple country rank) can easily be used for drawing the attention of a wider audience to problems of innovation performance.

In this article, we sketch such a multidimensional framework. It is applied by the Austrian Council for Research and Technology Development - the central advisory body of the Austrian Government for education, science, research and innovation policy affairs - for monitoring, measuring and evaluating the performance of Austria's national innovation system in international comparison. The paper aims to present an overview of the development of the measurement framework in co-operation with the Austrian Institute of Economic Research and in attunement with the responsible ministries. The article also intends to describe its application in the context of the Council's annual Reports on Austria's Scientific and Technological Capability.

The applied measurement framework for innovation performance takes into account country-specific conditions and provides information on both the current distance to strategic benchmarks as well as information on the distance to the benchmark at a given time horizon, based on extrapolating past growth trends. A matrix composed of the juxtaposition of current and future to target provides information able to guide policy priority setting, in terms of a measure of the effort required to reach targets (or the likelihood of reaching targets). Using this approach, the Austrian Council has been providing a sound source of evidence for an international comparison of Austria's innovation performance which supports evidence-based policy-making. 


\section{TOWARDS A FRAMEWORK TO MEASURE INNOVATION PERFORMANCE}

On 31 August 2009, the Austrian Council of Ministers agreed to set up an inter-departmental working group to elaborate a Strategy for research, technology and innovation (RTI Strategy). The aim was to define strategic goals and measures for Austrian RTI policy for the period up to 2020. The RTI Strategy with the title Becoming an Innovation Leader was adopted in March 2011. In its title, the document reflects the priority goal to be reached by 2020. ${ }^{2}$ The government has commissioned the Austrian Council for Research and Technology Development with the task of measuring the progress of the implementation of the strategy and monitoring Austria's performance in RTI compared to that of the leading countries in Europe and the world. Since then, the Council has been drawing up a yearly Report on Austria's scientific and technological capability ${ }^{3}$ to present the main findings of its monitoring activities. The first report was presented in June 2012.

The reports apply a framework to measure innovation performance that relies upon a thorough analysis of the RTI system, strategic goals set by the government, and standardised indicators to operationalise monitoring of target achievement. In a first step, a detailed countryspecific analysis of strengths and weaknesses of Austria's innovation performance was conducted, which was intended as groundwork for the subsequent definition of strategic goals compiled in a comprehensive RTI Strategy. This multi-year process of discussions and analyses consisted of three pillar stones:

- The "Austrian Research Dialogue"4 (2007-2008) was designed to be a broad, nationwide process of discourse and consultations with Austrian stakeholders for the purpose of further developing the innovation system and a knowledge-based society.

- The evaluation of Austria's research funding ${ }^{5}$ ("System Evaluation" 2008-2009) provided a profound assessment of the entire competitive R\&D funding system, along with recommendations for improvement by experts.

- The Council for Research and Technology Development elaborated evidence-based strategic proposals and recommendations for further development of the Austrian research and innovation system ("Strategy 2020" 2009). ${ }^{6}$

Based upon the results of these analytic processes, strategic goals for improving the Austrian innovation system were adopted in the aforementioned RTI Strategy and five performance areas (education, tertiary education, academic research, corporate R\&D as well as governance and funding of R\&D) were identified with particular catch-up potential. This is where our monitoring framework comes in: While some quantitative targets were set for each performance area (for example the goal to reach an R\&D quota of 3.76 percent by 2020), most goals with respect to the performance areas were only expressed in a qualitative way, so that we constructed targets from the average values of the group of Innovation Leaders (according to the European Innovation Scoreboard (EIS) at which the RTI Strategy is oriented). ${ }^{7}$ This means that some of our indicators use as target value the number which was already set in the RTI Strategy, while most use as target value the arithmetic average of the group of leading innovation countries as determined by the EIS.

In fact, any target value can be used; while an absolute value will be static, the average of a number of freely chosen peer countries will be dynamic in the sense that the target value changes according to the performance of the peer countries. This is similar to standardised rankings, with the exception that for our tailor-made approach peer countries can be chosen freely, presumably from a set of countries whose structures and performances are not too far away from the country to be monitored.

To construct targets, appropriate indicators had to be selected, in terms of relevance and reliability, but also data availability. For the purpose of measuring Austria's innovation performance, a set of 75 indicators were developed in co-operation with the Austrian Institute of Economic Research and discussed with the responsible ministries. ${ }^{8}$ The selected indicators are based on internationally used classifications of

2 The priority goal of the Strategy to become an Innovation Leader by 2020 is oriented at the European Innovation Scoreboard (EIS). As a Strong Innovator Austria currently ranks among the top 10 member states of the European Union. Austria's score amounted to 120 points according to ElS 2018, while the group of Innovation Leaders reached an average score of 135. For details see https://ec.europa.eu/growth/industry/innovation/facts-figures/scoreboards_en

3 All reports can be downloaded from https://www.rat-fte.at/performance-reports.html

4 The Research Dialogue was initiated by the Ministry of Science and Research. A synopsis (in German) can be downloaded here: https://bmbwf.gv.at/ forschung/national/standortpolitik-fuer-wissenschaft-forschung/oesterreichischer-forschungsdialog/

5 The "Evaluation of Government Funding in RTDI from a Systems Perspective in Austria" was commissioned by the Ministry of Transport, Technology and Innovation. The Synthesis Report (in English) can be downloaded here: https://www.bmvit.gv.at/service/publikationen/innovation/forschungspolitik/downloads/systemevaluierung/synthesis_report.pdf

$6 \quad$ The "Strategy 2020" was elaborated by the Austrian Council with the support of a Web-based discussion platform in order to deepen and intensify the process through virtual interaction with all relevant stakeholders and the RTI community. For the community-based innovation approach for strategy development see Gadner/Leo 2010. The Strategy 2020 (in English) can be downloaded here: https://www.rat-fte.at/strategy-2020.html

7 The term Innovation Leader refers to those EU countries in the top group in the annual European Innovation Scoreboard (EIS) of the European Commission. Today, the group comprises Denmark, Germany, Finland, Luxembourg, the Netherlands and Sweden. For the calculations the "innovation leaders' actual value" is used for every performance area.

8 It has to be mentioned that the processes of country analysis, target-setting and indicator choice enable collective learning and discussion processes at the national level, something which is completely absent from standardised innovation rankings but fosters the legitimacy of S\&T indicators (Barré 2010). In our case six ministries were involved in the process: The Federal Chancellery (BKA), the Ministry of Finance (BMF), the Ministry of Education, Art and Culture (BMUKK), the Ministry of Transport, Innovation and Technology (BMVIT), the Ministry of Science and Research (BMWF) and the Ministry of Economic Affairs, Family and Youth(BMWFJ). 
the OECD, Eurostat etc. and corresponding data portfolios. These are collected regularly on a national as well as on an international level. ${ }^{9}$ Every indicator corresponds to a strategic target of the RTI Strategy to operationalise goal achievement. ${ }^{10}$

For the development of the set of indicators it was important to focus on indicators suitable for better representing the conditions of the Austrian RTI system than for example those used by the EIS or other standardised rankings. This was deemed to be important by the Council since the EIS strongly focuses on inter-sectoral structural change and captures economic effects of innovation mainly by the growth of high-tech sectors; in contrast to this, the EIS underestimates effects of innovation activities in medium-tech-sectors, as intra-sectoral upgrading- improving innovation within a sector, rather than growing the share of innovation-intensive sectors in total output - is barely captured (Janger et al., 2017).

In fact, the EIS includes only few indicators for improvement across all existing sectors, i.e. intra-sectoral structural change or sectoral upgrading in less R\&D intensive sectors such as steel or automobile parts. Austria performs very well in less R\&D intensive sectors, which is why a picture not taking this aspect into account is rather incomplete. Moreover, the EIS indicators which could be interpreted as indicators of sectoral upgrading are based on the Community Innovation Survey (CIS). ${ }^{11}$ As the CIS indicators are very volatile, their explanatory power is limited. Statistically more stable indicators such as the export quality in technology-oriented sectors or R\&D intensity adjusted for the structural composition of an economy demonstrate only a relatively small gap to the leading innovation countries (for details see Austrian Council for Research and Technology Development 2014, pp. 10ff). Consequently, the indicators used within the framework adopted by the Austrian Council rely on more suitable indicators representing Austria's countryspecific characteristics. This does not prevent international comparison as these indicators are also available for other countries and in fact, the whole framework rests on international comparison with leading countries.

\section{VISUALISING INNOVATION PERFORMANCE}

The applied framework focuses on the degree to which the goals set out in the strategy have been achieved (static component, current distance to the goal) and on the degree to which the goals may be achieved in the future (dynamic component, probability of achieving the goal). While the current distance to the target simply reflects Austria's current performance relative to the target value (either as set by the RTI strategy or as the average level of the Innovation Leaders), the probability of achieving the goal extrapolates past growth trends to indicate where Austria's performance would be by the time horizon 2020. This is intended to guide policy priority setting and assumes a "business as usual scenario", i.e. that if no more policy interventions happen, trends continue as in the past. Extrapolating past growth trends is not used to forecast indicator values in the future, but to show the development over time of an indicator as an additional information for policy purposes see below the description of the four quadrants of figure 1.

This can be graphically displayed as the following example shows. Figure 1 provides a comprehensive overview of the performance within the analysed areas of the RTI system in relation to the selected peer countries which are as outlined above as those countries identified as "Innovation Leaders" by the EIS. This relates to the stated objective of the RTI strategy to catch up to the Innovation Leaders and is hence a policy choice rather than a choice based on an analysis of e.g. structural similarity.

The distance to target on the horizontal axis in figure 1 illustrates the current Austrian value and the distance to the respective target. It shows the ratio and the distance of the last available Austrian value to the national set target according to the RTI Strategy and the European Education and Training 2020 Strategy. ${ }^{12}$ If there is no target value, the target is constructed out of the last available average value for the current Innovation Leaders according to the EIS. This is due to the fact that catching up with the group of Innovation Leaders is a priority goal for Austria, as established in the RTI Strategy. The arrows show the movement of indicator values over time, with the origin of the arrow denoting the indicator value in the first measurement year and the end of the arrow pointing to the current value.

\footnotetext{
$9 \quad$ A detailed explanation of the indicators (including the strategic goals which they operationalise) as well as the underlying data and the calculations can be found in the Appendices of every Report on Austria's scientific and technological capability.

10 It has to be noted, that quantitative indicators cannot display all the objectives of the RTI strategy. This particularly applies to the performance area of governance structures of the RTI system. Thus, the indicator-based analysis has always been complemented with a qualitative evaluation of implemented measures and goal achievement.

11 The Community Innovation Survey (CIS) is a survey of innovation activity in enterprises. It is carried out biennial by EU member states and number of ESS (European Statistical System) member countries. Although it is designed to provide information on the innovativeness of sectors by type of enterprises, on the different types of innovation and on various aspects of the development of an innovation, such as the objectives, the sources of information, the public funding, the innovation expenditures etc, the compiling of the data is voluntary to the countries. This means that in different surveys or years different countries are involved. For details see https://ec.europa.eu/eurostat/web/microdata/community-innovation-survey

12 Following the suggestion of the Federal Ministry of Education, Arts and Culture at the time, target values of the European Education and Training 2020 Strategy have been used for some indicators operationalising targets within the education system.
} 


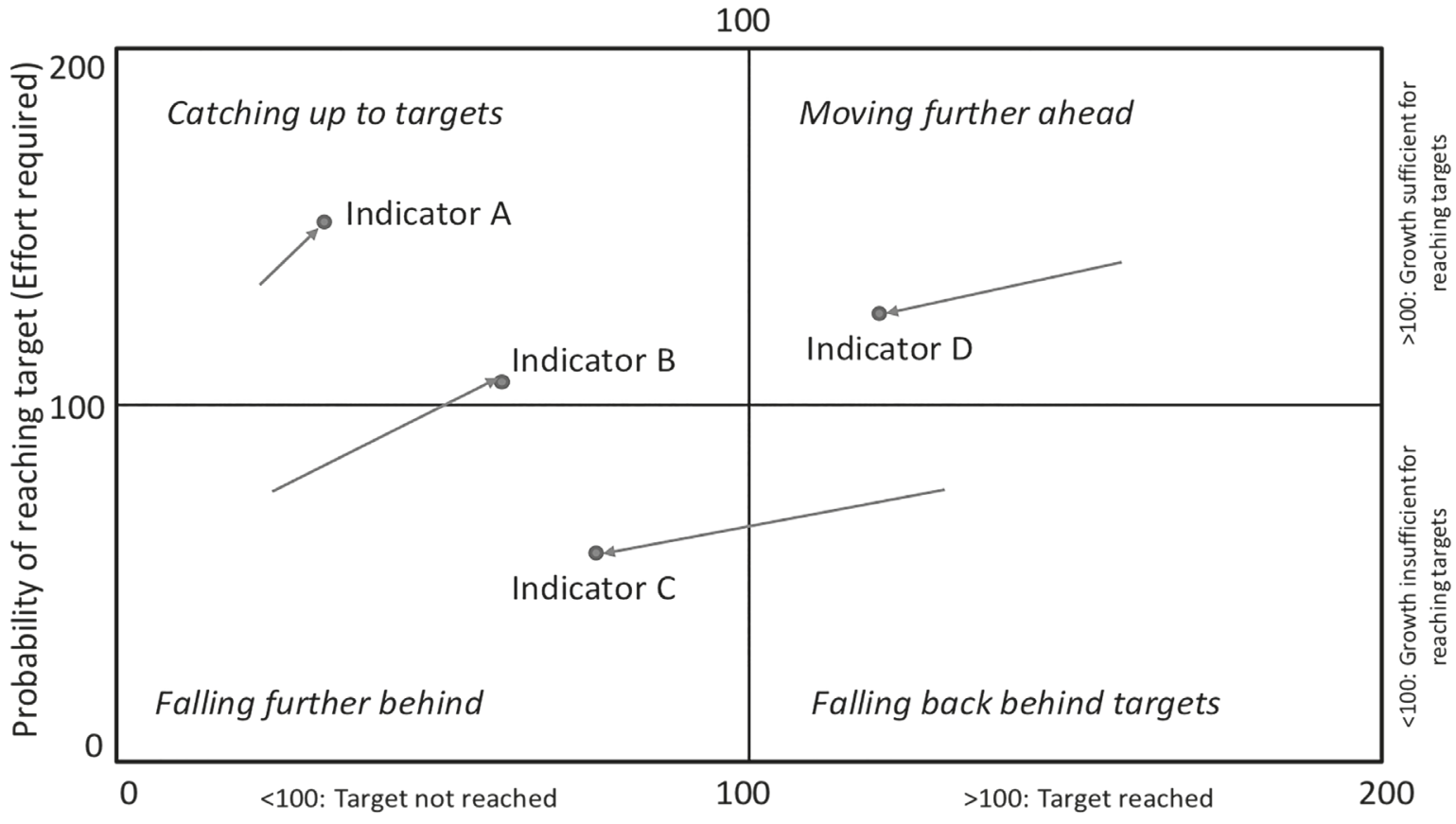

Current distance to target

Figure 1: Visualising innovation performance: Outcomes over time based on the combinations of current and future distance to target Source: Austrian Council for Research and Technology Development (2018): Report on Austria's Scientific and Technological Capability 2018. Vienna, p. 103.

The distance to target exhibits Austria's current performance level and reveals the current difference between performance achieved and target performance, but it says nothing about the changes or dynamics which are required for the goal to be achieved. Thus, an indicator which currently lies just below the target level could therefore deteriorate again due to a negative development. To put it another way, the exclusive comparison of the distances to target does not allow any conclusions with regard to the prospect of goal achievement. For this reason, the probability of reaching the target on the vertical axis was selected as the second dimension. It shows whether or not the past growth of the indicator is sufficient for goal achievement. It indicates the ratio of the average annual growth rate of the respective data series in the past and the projected value for Austria in 2020 to the target value for 2020 (under a business-as-usual assumption, see above). As target value for the calculation of growth, if no quantitative target value was set in the RTI strategy for the respective goal, the projected value for 2020 of the Innovation Leaders will be used, and not their actual value. This in turn is determined on the basis of the average growth rates of the comparison countries in the past.

All indicators can be interpreted in the same direction, i.e. values above 100 signal goal achievement, values below 100 a corresponding distance to the goal. Indicators with a probability of reaching the goal below 100 - i.e. below the horizontal line at 100 - are based on past growth trends unlikely to reach the target by the end of the time horizon; indicators with a value above 100 - above the horizontal line - are likely to reach the target value. The standardisation of the values is achieved as follows: The Austrian value is divided by the respective target value and multiplied by 100 . If performance improvements are accompanied by a decline in the indicator values, such as with the unemployment rate, for example, the values would be inverted (i.e. target value in the numerator, Austrian value in the denominator), in order to retain the interpretation of "greater equal to $100=$ goal achievement". Values above 200 are limited in the graphics to 200 .

If an indicator is located in one of the two quadrants on the left side, this means that Austria has not yet achieved the set goal. For indicators in the bottom left corner this will very probably also remain unchanged. Hence, due to the weak growth rate in these performance areas, Austria will not achieve the goal by 2020. Consequently, without additional measures the Innovation Leaders are very likely to remain in front. Measures that are suitable to increase performance in this area should therefore be handled as a special priority. Indicators in the top left area are catching up, which could result in achieving the goal by 2020, as the Austrian development dynamic is greater than that of the comparison countries. In these performance areas no further measures would be required, always assuming that trends go on as in the past.

Indicators located in the two right quadrants show that the corresponding goals have already been achieved. Indicators in the top right corner signify that Austria has achieved the goal and in all likelihood will also remain in front until 2020 due to the high growth rates, provided the growth of the comparison countries remains within the expected range. Thus, there is currently no need for further action. Indicators in the quadrant on the right bottom signal that Austria's growth is insufficient to maintain its edge ahead of the Innovation Leaders in the long term. Accordingly, the development should be observed very closely here to also counteract in good time where required. 


\section{ILLUSTRATING THE USE OF THE FRAMEWORK WITH A PRACTICAL EXAMPLE}

To illustrate how the framework is used in practice, an example from the Report on Austria's scientific and technological capability 2015 is presented below. ${ }^{13}$ Figure 2 shows the indicator-based results of the approach for the area of research and innovation in the corporate sector for the current distance to the target and the probability of reaching the target. The tail of each indicator depicts the past development from 2010 until 2015

The figure reveals at a glance the developments of both the current distance to the goal and the probability of reaching the goal by 2020 in the performance area of research and innovation in the corporate sector within the Austrian RTI system. It becomes clear that at the given time there was still considerable potential to optimise performance and increase efficiency in the corporate sector. While the six indicators in the right upper quadrant had indeed already reached their target or the level of the Innovation Leaders, the majority of indicators still continued to be within the bottom left quadrant indicating a performance below the average level of the peers and expected to fall further behind. Judging by the current trends, and with no additional measures taken the indicator in the bottom right corner will deteriorate and fall below the target level by 2020. Those indicators in the top left quadrant display dynamic developments and will most likely continue catching up and reach the target level by the year 2020 .

In sum, the presented performance area of research and innovation in the corporate sector at the given time had the third-smallest goal distance of the six areas analysed and the highest probability to achieve the goal. Overall, goal distance was deemed to be within reach by 2020 - provided the trends continued to develop as they have in the past. However, many indicators, such as 'Competition policy' or 'Venture capital intensity', were well below the target level and displayed insufficient or retrograde dynamics to catch-up with the group of leading countries. Furthermore, performance in key sub-areas, such as start-up dynamics and venture capital intensity, remained extremely weak in comparison to the Innovation Leaders. Based on this picture, the relevant fields of action were addressed in the Council's report - including concrete policy recommendations for improving Austria's innovation performance within the specific areas.

It is important to mention that the Council of Ministers commissioned the Council for Research and Technology Development to elaborate the annual Reports on Austria's scientific and technological capability in

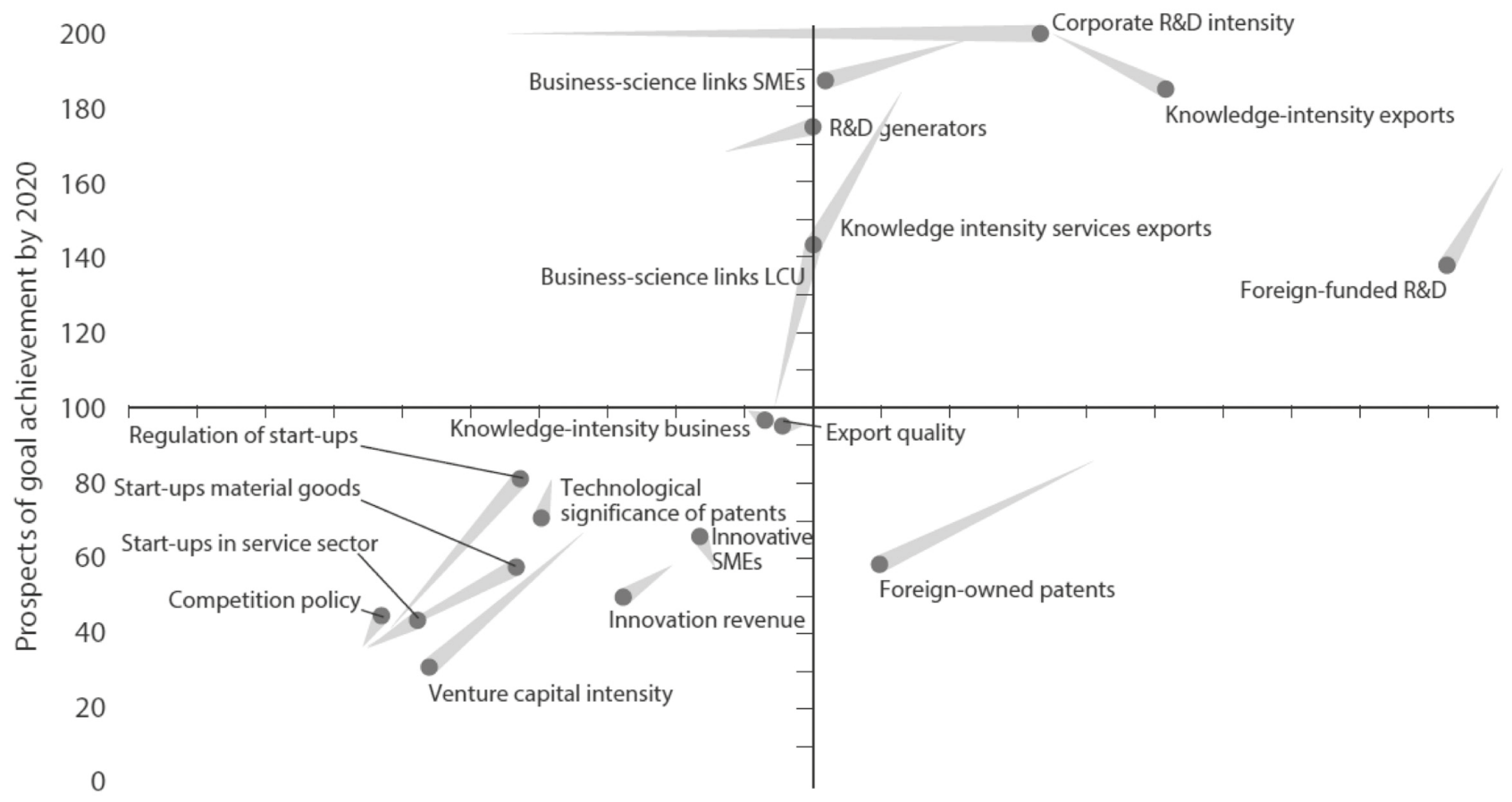

Figure 2: Development of distance to targets and probability to reach the target in the area of research and innovation in the corporate sector, 2010 to 2015 Source: Austrian Council for Research and Technology Development (2015): Report on Austria's Scientific and Technological Capability 2015. Vienna, p. 47. 
order to send it to the Austrian Parliament. There it is debated in the parliamentary Committee on Research, Technology and Innovation. It is also presented publicly and published on the Councils Web-page. With this approach it was intended to put the political and public debate on education, science, research and innovation policy affairs on a sound evidence-based footing.

\section{CONCLUDING REMARKS}

The described measurement framework is a sound basis for a meaningful monitoring of national RTI policies and innovation performance, although it requires more work than using standard indicators as outlined above: first, goals have to be set, possibly within a strategybuilding exercise. Goal-setting requires an analysis of the strengths and weaknesses of a country. Once goals are set, suitable indicators can in a second step be drawn from available sources, such as OECD data; when no ready-made indicators exist, new indicators would have to be built, which needs more effort and above all the corresponding data. Once goals and indicators are in place, progress over time can be monitored, assessing the impact of any policies implemented to reach the goals.

As we have demonstrated, the sketched framework for measuring innovation performance not only refers to Austria's country-specific conditions but also facilitates a dynamic view of past and future developments. While standard rankings just give a static snapshot of one performance point in time, the presented approach yields the possibility to show where current dynamics of innovation performance may lead to in the near future. Growth trends of single indicators may be positive or negative so that a yearly snap shot on its own is of little use to policymakers. Different policy priorities apply to areas, where a country lags behind, but catches up quickly as compared to those, where a country lags behind with a further falling tendency. In the first case, no further action is needed, in the second, alarm bells should be ringing.

The limitations of the proposed framework for policy makers are that the framework needs to be custom-made for national purposes and it requires more resources first for the analysis of national performance and then for national target-setting or strategy-building. Like a tailormade suit, the framework fits better but is more expensive and timeconsuming. The benefits of appropriately reflecting country strengths and weaknesses may however largely outweigh the costs of not only relying on standardised indicator frameworks. Moreover, common to all indicator-based measurement frameworks, it is a quantitative framework, meaning that international benchmarking relies on available data for indicator-building. Country-specific challenges lacking internationally comparable data can only be addressed in a qualitative way.

For the Austrian Council, the described monitoring framework and the indicator-based measurement of innovation performance has been a basis from which to draw conclusions about Austria's scientific and technological capability in relation to the leading innovation nations. With this evidence-based analysis of strengths and weaknesses of the Austrian RTI system, the most pressing priority fields of action have been identified and dealt with in the Council's annual reports and policy recommendations. Additionally, the Council uses the described approach for the strategic monitoring of the realisation of the federal government's RTI strategy as well as the assessment of efficiency and effectiveness of the implemented measures. The measurement framework can also be adopted in other countries, provided that there are suitable strategybuilding and performance-analysing excercises. It may be an interesting tool for policy-makers elsewhere, allowing them to focus on countryspecific issues rather than on insights based on standardised innovation rankings.

\section{REFERENCES}

Aghion, P., David, P. A. and Foray, D. (2009): Science, technology and innovation for economic growth: Linking policy research and practice in "STIG Systems", Res. Policy, 2009, 38(4), pp. 681-693.

Androsch, H. and Gadner, J. (2015): Designing the future. In: Austrian Council for Research and Technology Development (ed.): Designing the future: Economic, societal and political dimensions of innovation. Echomedia, Vienna, pp. 8-39.

Austrian Council for Research and Technology Development (2018): Report on Austria's Scientific and Technological Capability 2018. Vienna.

Austrian Council for Research and Technology Development (2015): Report on Austria's Scientific and Technological Capability 2015. Vienna.

Austrian Council for Research and Technology Development (2014): Report on Austria's Scientific and Technological Capability 2014. Vienna.

Barré, R. (2010): Towards socially robust S\&T indicators: indicators as debatable devices, enabling collective learning. Res. Eval., 2010, 19(3), pp. 227-231

Edler, J. and Fagerberg, J. (2017): Innovation policy: what, why, and how. Oxf. Rev. Econ. Policy, 2017, 33(1), pp. 2-23.

Edquist, C., Zabala-Iturriagagoitia, J. M., Barbero, J. and Zofío, J. L (2018): On the meaning of innovation performance: Is the synthetic indicator of the Innovation Union Scoreboard flawed? Research Evaluation, 2018, 27(3), pp. 196-211

Gadner, J. and Leo, H. (2010): Innovation Policy Counseling 2.0: How Open and Community-Based Innovation Processes Promote Political Decision Making. bridges, vol. 28, December 2010 / Feature Article. Online: https://ostaustria.org/bridges-magazine/volume-28-december20-2010? start $=20$

Grupp, H. and Schubert, T. (2010): Review and new evidence on composite innovation indicators for evaluating national performance. Res. Policy, 2010, 39(1), pp. 67-78.

Janger, J., Schubert, T., Andries, P., Rammer, C. and Hoskens, M. (2017): The EU 2020 innovation indicator: A step forward in measuring innovation outputs and outcomes? Res. Policy, 2017, 46(1), pp. 30-42.

Schibany, A. and Streicher, G. (2008): The European Innovation Scoreboard: drowning by numbers? Sci. Public Policy, 2008, 35(10), pp. 717732. 


\section{AUTHORS}

\section{JOHANNES GADNER}

Austrian Council for Research and Technology Development

Pestalozzigasse 4/D1, 1010 Vienna

https://www.rat-fte.at/home-en.html

E: j.gadner@rat-fte.at

\section{JÜRGEN JANGER}

Austrian Institute of Economic Research

Arsenal, Object 20, 1030 Vienna

https://www.wifo.ac.at/en

E: juergen.janger@wifo.ac.at

\section{KEYWORDS:}

monitoring, innovation performance, RTI policies, measurement framework, international comparison 